\title{
Refractivity and temperature climate records from multiple radio occultation satellites consistent within $0.05 \%$
}

\author{
U. Foelsche ${ }^{1}$, B. Scherllin-Pirscher ${ }^{1,2}$, F. Ladstädter ${ }^{1}$, A. K. Steiner ${ }^{1}$, and G. Kirchengast ${ }^{1}$ \\ ${ }^{1}$ Wegener Center for Climate and Global Change (WEGC) and Institute for Geophysics, Astrophysics, and Meteorology/Inst. \\ of Physics (IGAM/IP), University of Graz, Graz, Austria \\ ${ }^{2}$ Advanced Study Program, National Center for Atmospheric Research (NCAR) and COSMIC Project Office, \\ University Corporation for Atmospheric Research (UCAR), Boulder, CO, USA
}

Received: 14 February 2011 - Published in Atmos. Meas. Tech. Discuss.: 7 March 2011

Revised: 13 July 2011 - Accepted: 28 August 2011 - Published: 28 September 2011

\begin{abstract}
Data consistency is an important prerequisite to build radio occultation (RO) climatologies based on a combined record of data from different satellites. The presence of multiple RO receiving satellites in orbit over the same time period allows for testing this consistency. We used RO data from CHAMP (CHAllenging Minisatellite Payload for geoscientific research), six FORMOSAT-3/COSMIC satellites (Formosa Satellite Mission 3/Constellation Observing System for Meteorology, Ionosphere and Climate, F3C), and GRACE-A (Gravity Recovery and Climate Experiment). We show latitude-altitude-resolved results for an example month (October 2007) and the temporal evolution of differences in a climate record of global and monthly means from January 2007 to December 2009. Latitude- and altitude-resolved refractivity and dry temperature climatologies clearly show the influence of different sampling characteristics; monthly mean deviations from the multi-satellite mean over the altitude domain $10 \mathrm{~km}$ to $30 \mathrm{~km}$ typically reach $0.1 \%$ and $0.2 \mathrm{~K}$, respectively. Nevertheless, the 3 -yr average deviations (shorter for CHAMP) are less than $0.03 \%$ and $0.05 \mathrm{~K}$, respectively. We find no indications for instrument degradation, temporal inhomogeneities in the RO records, or temporal trends in sampling patterns. Based on analysis fields from ECMWF (European Centre for MediumRange Weather Forecasts), we can estimate - and subtract - the sampling error from each monthly climatology. After such subtraction, refractivity deviations are found reduced to $<0.05 \%$ in almost any month and dry temperature devi-
\end{abstract}

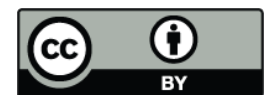

Correspondence to: U. Foelsche (ulrich.foelsche@uni-graz.at) ations to $<0.05 \mathrm{~K}(<0.02 \%$ relative) for almost every satellite and month. 3-yr average deviations are even reduced to $<0.01 \%$ and $<0.01 \mathrm{~K}$ (CHAMP: $-0.05 \mathrm{~K}$ ), respectively, establishing an amazing consistency of RO climatologies from different satellites. If applying the same processing scheme for all data, refractivity and dry temperature records from individual satellites with similar bending angle noise can be safely combined up to $30 \mathrm{~km}$ altitude (refractivity also up to $35 \mathrm{~km}$ ) to a consistent single climate record of substantial value for climate monitoring in the upper troposphere and lower stratosphere.

\section{Introduction and context}

Accurate, consistent, long-term data are required for any attempt to detect, understand, and attribute climate variability and change. GNSS (Global Navigation Satellite System) Radio Occultation (RO) data (Kursinski et al., 1997) are meanwhile recognized as a promising source for such a climate record in the upper troposphere and lower stratosphere. The signal phase measurements as function of time are based on precise atomic clocks and can be traced to the international standard for the second (Leroy et al., 2006a). Atmospheric profiles are not derived from absolute values (excess phase) but from phase change profiles (Doppler shift). Therefore, RO (raw) measurements require no external calibration and only short-term measurement stability over the occultation event duration (1-2 min), which is provided by very stable oscillators onboard the GNSS satellites. Potential residual GNSS clock errors and clock errors on the receiving satellites

Published by Copernicus Publications on behalf of the European Geosciences Union. 
can be corrected by relating the measurements to even more stable oscillators on the ground (Hardy et al., 1994; Hajj et al., 2002). With this "self-calibration", it should be possible to combine data from different sensors and different occultation missions without need for inter-calibration and overlap, provided that the same data processing scheme is used (von Engeln, 2006; Ho et al., 2009b) and spatio-temporal sampling (Foelsche et al., 2008a; Pirscher et al., 2007) is well understood.

During the last few years, RO measurements have been increasingly used by weather centers around the globe, and they show a surprisingly large positive impact on the quality of atmospheric analyses (Cardinali, 2009), partly due to the fact that they are the only satellite data (so far) that can be assimilated without bias correction (Healy, 2008).

The climate monitoring utility of RO data has been assessed with simulation studies (e.g. Yuan et al., 1993; Steiner et al., 2001; Foelsche et al., 2003, 2008b; Leroy et al., 2006b; Ringer and Healy, 2008). RO records have been successfully validated against (A)MSU data (Schroeder et al., 2003; Steiner et al., 2007; Ho et al., 2009a) and data from GOMOS (Global Ozone Monitoring for Occultation of Stars) and MIPAS (Michelson Interferometer for Passive Atmospheric Sounding) on ENVISAT (Gobiet et al., 2007). They have also been validated against climatological analyses (Gobiet et al., 2005, 2007; Foelsche et al., 2008a). Their ability for monitoring tropopause parameters has been demonstrated by Schmidt et al. (2005), Borsche et al. (2007), and Foelsche et al. (2009). Von Engeln et al. (2005) and Sokolovskiy et al. (2006) have investigated monitoring of the height of the atmospheric boundary layer with RO data. First studies on climate trends and variability have been performed by Steiner et al. (2009) and Schmidt et al. (2010).

The German research satellite CHAMP (Challenging Minisatellite Payload for geoscientific research) has (almost) continuously been recording RO profiles (Wickert et al., 2001, 2004) from September 2001 to October 2008. RO data from CHAMP, covering more than $7 \mathrm{yr}$, provide the first opportunity to create RO based multi-year climatologies. The number of RO profiles is sufficient to build monthly and seasonal mean, zonal mean climatologies (Foelsche et al., 2005, 2008a). The RO receiver on satellite A from the USGerman GRACE mission (Gravity Recovery and Climate Experiment) has been continuously activated in May 2006 (Beyerle et al., 2005).

Formosat-3/COSMIC (Formosa Satellite Mission 3/Constellation Observing System for Meteorology, Ionosphere, and Climate; F3C hereafter) is a Taiwan/US RO mission consisting of six receiving satellites (Schreiner et al., 2007; Anthes et al., 2008). In April 2006, all six F3C satellites were originally launched into the same parking orbit with $\sim 515 \mathrm{~km}$ orbit altitude and then sequentially raised to their final orbit altitudes of $\sim 800 \mathrm{~km}$. At this altitude the precession due to the oblateness of the Earth is smaller than in the parking orbit, leading to an intended deployment of the orbit planes to a final separation of $30^{\circ}$. Five F3C satellites are in their final orbits (with optimal distribution of RO events in space and local time), but orbit raising for Flight Model 3 (FM-3) has been stopped in July 2007 due to problems with the solar panels (Anthes et al., 2008).

The European operational meteorological satellite MetOpA was launched into a sun-synchronous orbit in October 2006. One of the eleven scientific instruments is the "GNSS Receiver for Atmospheric Sounding" (GRAS), which performs the first operational RO measurements (Luntama et al., 2008; von Engeln et al., 2009). MetOp-A will be followed by two almost identical satellites, both equipped with GRAS receivers. Together, the MetOp satellites will therefore provide RO measurements with essentially the same instruments over a period of about $15 \mathrm{yr}$. Since a F3C follow-on mission is currently planned, as are several RO missions of opportunity, a continuous RO data stream can be anticipated at least until 2020.

RO data from these satellites allow for testing the consistency of climatologies from multiple satellites. Hajj et al. (2004), Schreiner et al. (2007), and Ho et al. (2009a) have confirmed the consistency of RO data from different satellites by comparing closely co-located RO profiles. In Foelsche et al. (2009) we have developed an alternative approach, by comparing global climatologies from different satellites. Here we advance those results, inspect more satellites, and focus on the temporal evolution of differences in global monthly mean climatologies, with and without sampling error estimates subtracted, from January 2007 to December 2009. Data and methods are explained in Sect. 2, the results on the consistency of RO climatologies are presented and discussed in Sect. 3, followed by conclusions in Sect. 4.

\section{Data and methods}

At WEGC we have developed a retrieval scheme for climate applications. Background information, which is needed for high altitude initialization in the step from bending angle to refractivity, is introduced in a transparent way (Gobiet and Kirchengast, 2004; Borsche et al., 2006; Gobiet et al., 2007; Foelsche et al., 2008a; Pirscher, 2010). The profile retrieval, termed "Occultation Processing System" (OPS; current version: 5.4), starts from excess phase data for each occultation event, including precise position and velocity information for the transmitting and receiving satellites ("level 1 data" provided by different processing centers). Background information is only introduced at bending angle level, by performing statistical optimization at altitudes above $30 \mathrm{~km}$ : the retrieved bending angle profiles and background information are combined using an inverse covariance weighting approach (Rieder and Kirchengast, 2001; Healy, 2001). As background we use short-term forecasts from the European Centre for Medium-Range Weather Forecasts (ECMWF). Ionospheric correction is performed 
via a linear combination of bending angles (Vorob'ev and Krasil'nikova, 1994). A concise summary description of OPSv5.4 was provided by Steiner et al. (2009), a detailed description by Pirscher (2010).

The same profile retrieval (OPSv5.4) has been applied to the input data from all satellites. For the results shown here we used excess phase and orbit data (level 1 data) provided by UCAR/CDAAC (COSMIC Data Analysis and Archive Center), Boulder, CO, USA, for CHAMP (UCAR version 2009.2650 for the entire record), GRACEA (version 2007.3200 until May 2009, version 2009.2650 from June 2009 until December 2009) and all six F3C satellites (version 2007.3200 until March 2009, version 2009.2650 from April 2009 until December 2009), respectively. MetOp/GRAS bending angle data are operationally available, but unfortunately no excess phase and orbit data (which are needed for our retrieval). We will not show MetOp/GRAS climatologies before these data become available, but we have received MetOp/GRAS data for a single month, which have been processed in offline-mode (A. v. Engeln, EUMETSAT, personal communication, 2010). With this data set we could at least address the bending angle quality at high altitudes (see Sect. 3.1) and obtained very reasonable results, which are in line with those by von Engeln et al. (2009).

WEGC RO climatologies of the atmospheric parameters bending angle, (microwave) refractivity, dry pressure, dry geopotential height, and dry temperature are obtained by "binning and averaging" with the CLIPS (Climate Processing System, version 1.3) software tool (Pirscher, 2010), using the approach explained by Foelsche et al. (2008a) and (2009). All RO profiles in a predefined geographic domain ("bin") are sampled and averaged (weighted by the cosine of the latitude), using a common (mean-sea-level) altitude grid with regular $200 \mathrm{~m}$ spacing. For single-satellite climatologies we use "fundamental" bins with $5^{\circ}$ latitudinal and $60^{\circ}$ longitudinal width, which are averaged in longitude to build zonal mean monthly mean climatologies. Cosine weighting within the fundamental bins is performed, because the latitudinal distribution of RO data of all current missions (with high orbit inclinations) is closer to "equal numbers per latitude" than to "equal numbers per area" (for the latter "no weighting" would be the appropriate approach). With a latitudinal width of $5^{\circ}$ the effect of cosine weighting is, however, minimal. Our basic latitudinal resolution is $10^{\circ}$ : each of the 18 latitude bands (pole to pole) contains two $5^{\circ}$ bands, and the mean profiles for these two bands are averaged, weighted with the surface area. Compared to direct averaging (within $10^{\circ}$ zonal bands), our spatial averaging approach slightly reduces the effect of uneven sampling within the latitude bands. Larger-area aggregation, up to global, also uses weighting by surface area.

Seasonal climatologies are obtained by averaging three monthly mean climatologies, annual climatologies by averaging twelve monthly mean climatologies within a calendar year. In addition we provide error estimates, like the systematic difference between retrieved and co-located reference (the latter from ECMWF analyses), the standard deviation of the retrieved parameter, and the estimated sampling error, caused by undersampling of the "true" spatial and temporal variability (for more details see Foelsche et al., 2008a, Pirscher, 2010). All WEGC OPSv5.4/CLIPSv1.3 climatologies are available online via http://www.globclim.org.

\section{Results and discussion}

\subsection{Bending angle quality at high altitudes}

We estimate the RO data quality based on bending angle statistics in the mesosphere, at impact heights (impact parameter minus local radius of curvature) between $65 \mathrm{~km}$ and $80 \mathrm{~km}$ (Pirscher, 2010). Here, the contribution from the neutral atmosphere is almost negligible and measurement noise and ionospheric residuals dominate. For data from the same day we can expect that the residual ionospheric noise is very similar for the different satellites and that differences in measurement noise are dominated by the different qualities of the RO receivers and antennas under consideration as long as the same differencing scheme is used for the removal of clock errors. All CHAMP and F3C excess phase data used in this study have been obtained using "singledifferencing": in addition to the occulted GNSS satellite, a second GNSS satellite is observed to remove clock errors on the receiving satellite (Schreiner et al., 2009). This reference link adds, however, additional ionospheric noise. MetOp is equipped with an ultra stable oscillator. Clock errors are therefore so small that high-quality data can be obtained without performing differencing at all ("zero-differencing"). GRACE-A data at CDAAC are also processed using zerodifferencing (W. Schreiner, UCAR Boulder, personal communication, 2009).

Figure 1 shows, for all satellites under consideration, time series of the daily median bending angle bias with respect to the MSIS-E climatology and daily median noise The MSISE climatology (Hedin, 1991) is not the "truth", but it serves as a good reference at the heights above $65 \mathrm{~km}$ for those very small bending angles. A small negative bias could indeed be expected due to uncorrected ionospheric residuals (Sokolovskiy et al., 2009). The median bending angle values for all satellites in the overlap period are extremely consistent, the mean values for all six F3C satellites (over the available time period) equal $-0.14 \mu \mathrm{rad}$ with respect to MSIS-E climatology. There are no visible temporal inhomogeneities; even after seven years in orbit data from CHAMP are still of the same quality as those from the recently launched F3C constellation. Even though the CHAMP record extends from high solar activity in 2002 to very low solar activity in 2008 there is no trend in the systematic differences to the MSIS-E climatology. Interesting features are 


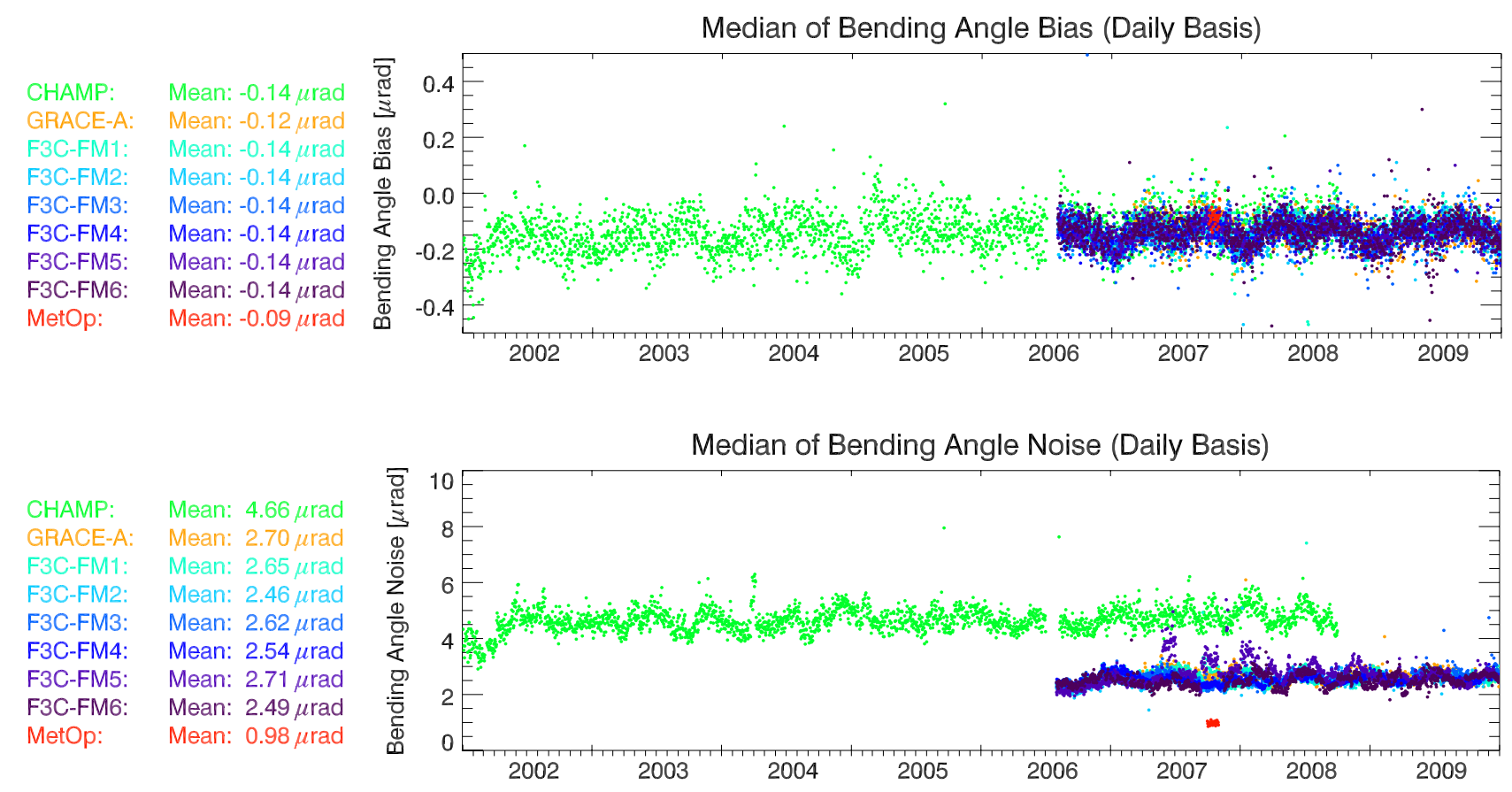

Fig. 1. Daily median bending angle bias with respect to the MSIS-E climatology (top) and daily median bending angle noise (bottom) for nine different satellites (listed left; showing also for each satellite the time-averaged mean value from its full period of observations).

annual and semi-annual cycles with respect to MSIS-E. The mean value for MetOp/GRAS $(-0.09 \mu \mathrm{rad})$ refers only to October 2007, where the semi-annual cycle shows a maximum. The value is therefore also consistent with those from the other satellites.

CHAMP RO measurements started in August 2001, but there have been several changes in the receiver software until March 2002 (Wickert et al., 2004). From this time onwards CHAMP RO data show a noise level (standard deviation) of about $4.7 \mu \mathrm{rad}$ (Fig. 1, bottom), which is distinctly larger than the noise in F3C and GRACE-A data (from about $2.5 \mu \mathrm{rad}$ to $2.7 \mu \mathrm{rad})$. This reflects the higher receiver quality on the F3C satellites, but also the benefit of zero-differencing in terms of less noise in case of GRACE-A (see Sect. 2), since the RO receiver on GRACE-A is similar to the one on CHAMP (Beyerle et al., 2005). The noise in MetOp/GRAS bending angle data is even smaller (about $1.0 \mu \mathrm{rad}$ ), but this is in part due to the fact that MetOp/GRAS data have also been obtained using zero-differencing.

\subsection{Consistency of refractivity climatologies}

In Foelsche et al. (2009) we adopted the approach to look at systematic differences between seasonal zonal mean climatologies from different satellites. This is a rigorous test of the consistency, since these differences contain the sampling errors of both climatologies ( $\mathrm{F} 3 \mathrm{C}$ satellites in their final constellation, e.g., never simultaneously sample the same region of the atmosphere). We showed that the predominant part of such differences arises indeed from different sampling of the atmosphere. Figure 2 illustrates this effect based on deviations of monthly mean refractivities from the multisatellite mean (i.e. averaging the climatologies of all satellites involved) in October 2007. It is most pronounced at high latitudes, where high atmospheric variability leads to values exceeding $2 \%$ (due to the exponential decrease of refractivity with altitude we show relative errors).

The sampling error (undersampling in space and time) can, however, be quantitatively estimated when an adequate representation of the "true" spatial and temporal variability of the atmosphere is available and the information on the locations and times of RO events is used (Foelsche et al., 2008a; 2009). As a proxy for the "true" evolution we use ECMWF analyses, whose four time layers per day are sufficient to sample the diurnal cycle and subdiurnal variations up to the semidiurnal cycle. We estimate the sampling error by comparing climatologies derived from vertical ECMWF profiles at the RO times and locations with climatologies derived from the complete 4D ECMWF field. This allows computing "double-differences", where we subtract the estimated sampling error fields from both single-satellite climatologies before we then difference the sampling-error-corrected climatologies. Even though these double differences contain the errors in the estimation of the sampling errors for both climatologies the results are striking (Fig. 3): relative refractivity differences are now smaller than $0.25 \%$ almost everywhere in the considered domain between $8 \mathrm{~km}$ and $35 \mathrm{~km}$ altitude. This very good agreement shows furthermore 
Oct 2007: Deviations of Refractivity
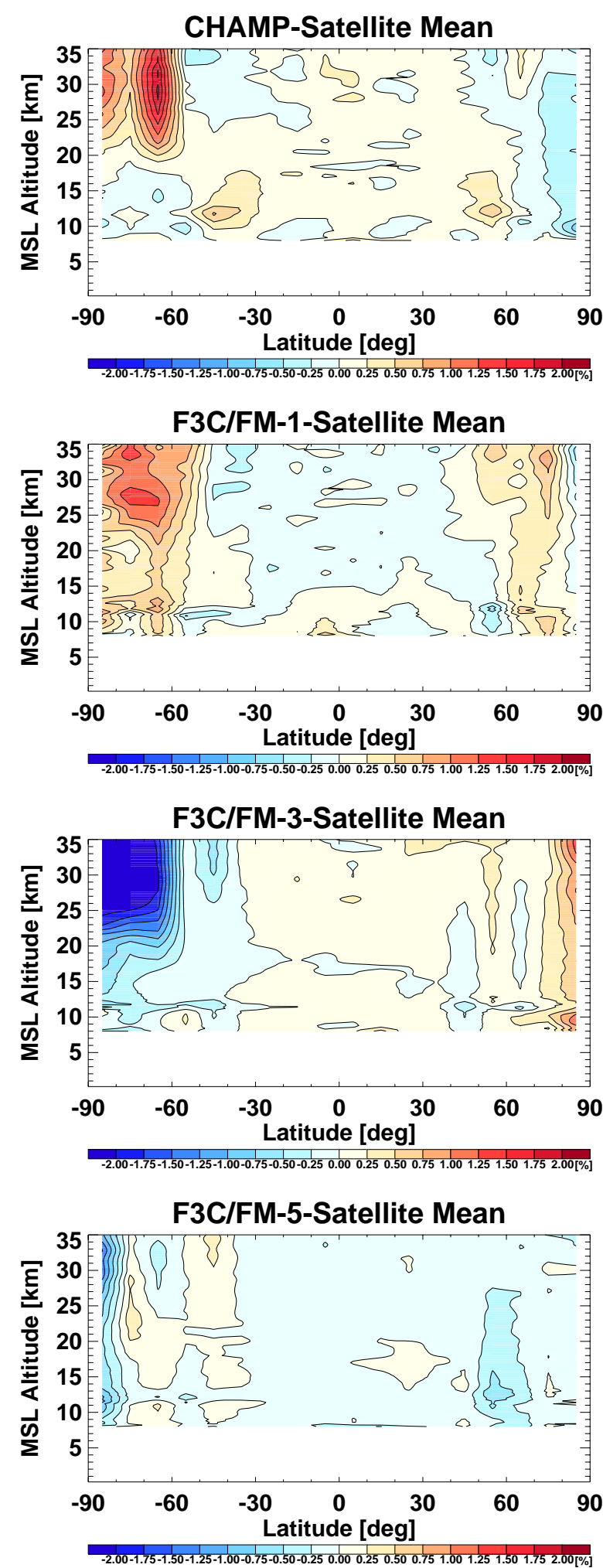

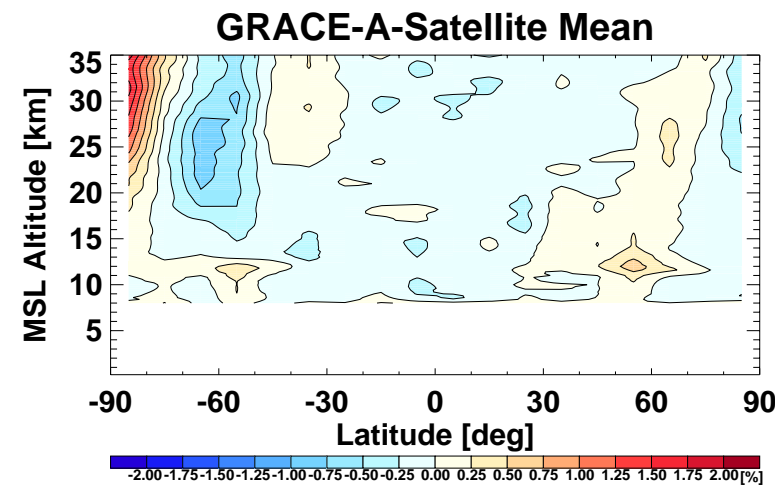

F3C/FM-2-Satellite Mean

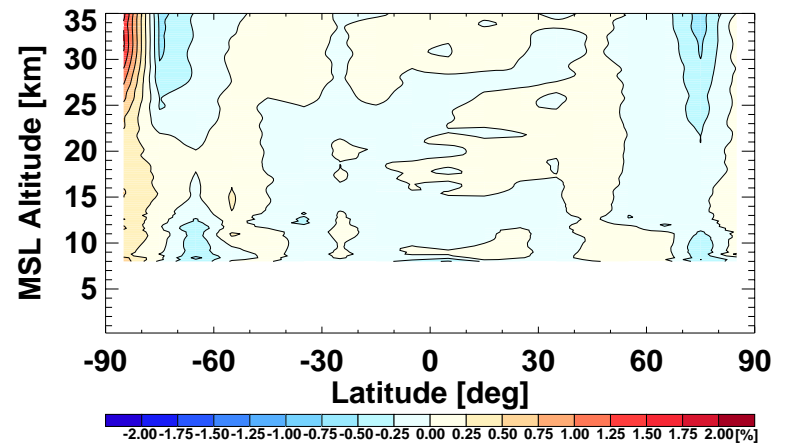

F3C/FM-4-Satellite Mean

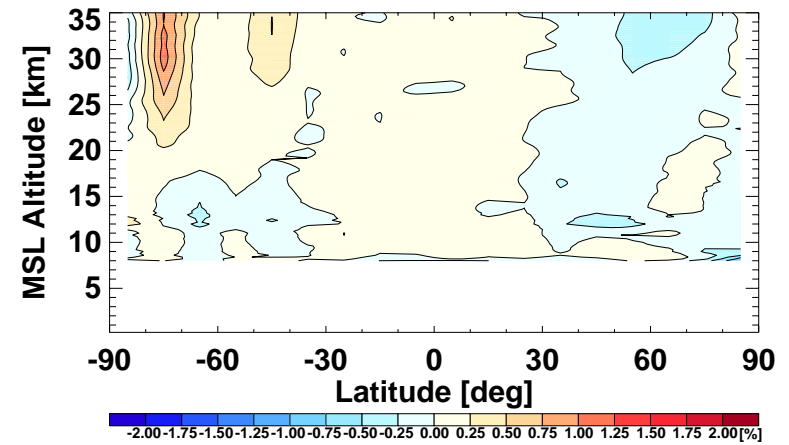

Fig. 2. Monthly mean relative refractivity differences with respect to the multi-satellite mean for October 2007 for seven satellites (name in panel titles, for this month there are no F3C/FM6 data available). 


\section{Oct 2007: Deviations of Refractivity (Sampling Error Subtracted)}
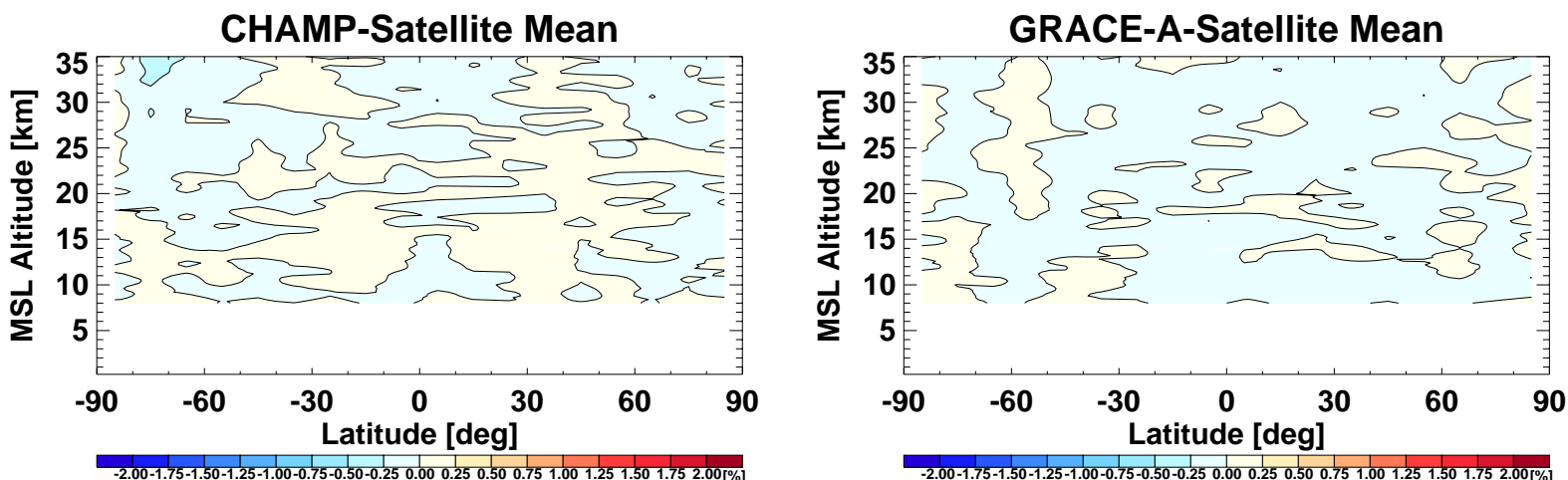

F3C/FM-1-Satellite Mean
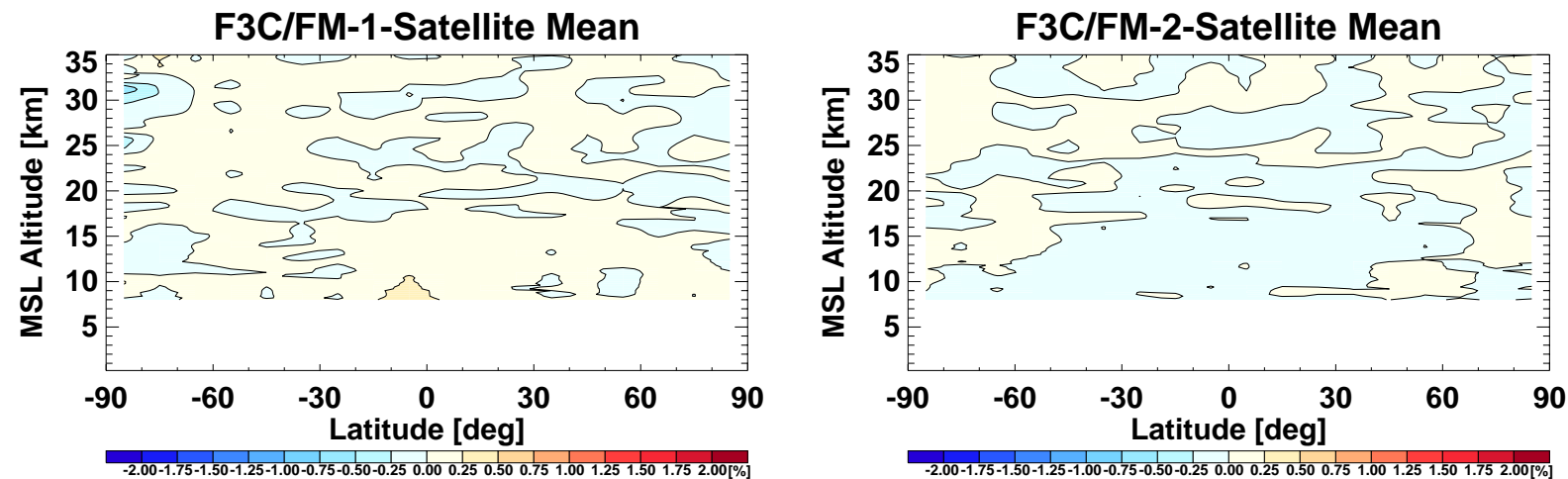

F3C/FM-3-Satellite Mean
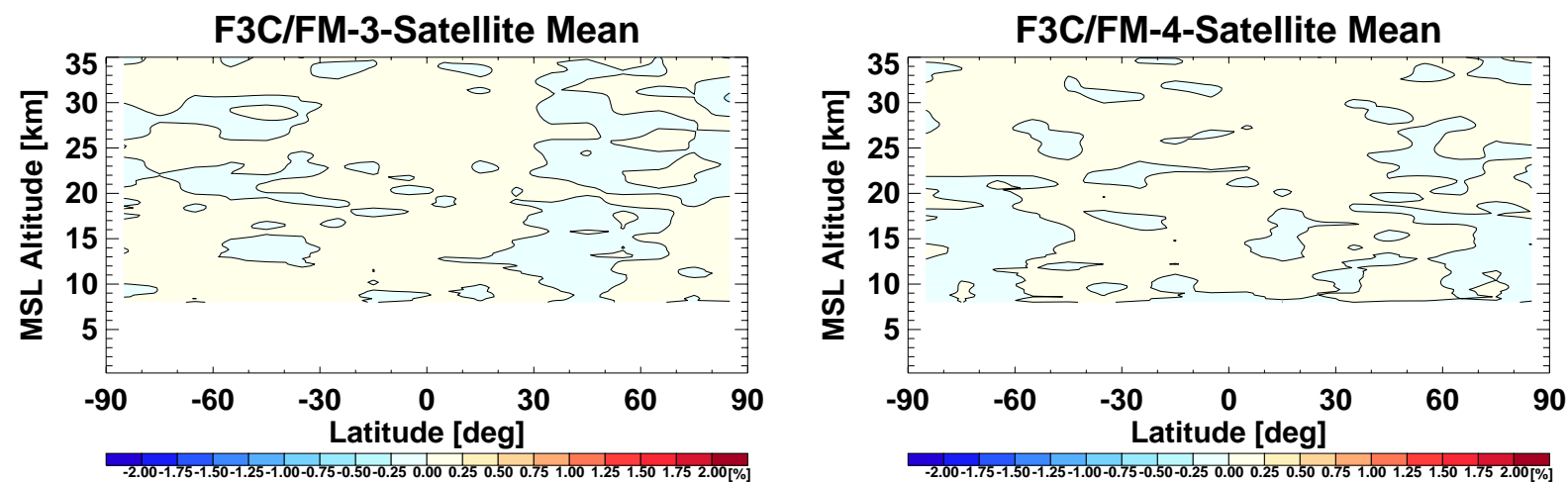

\section{F3C/FM-5-Satellite Mean}

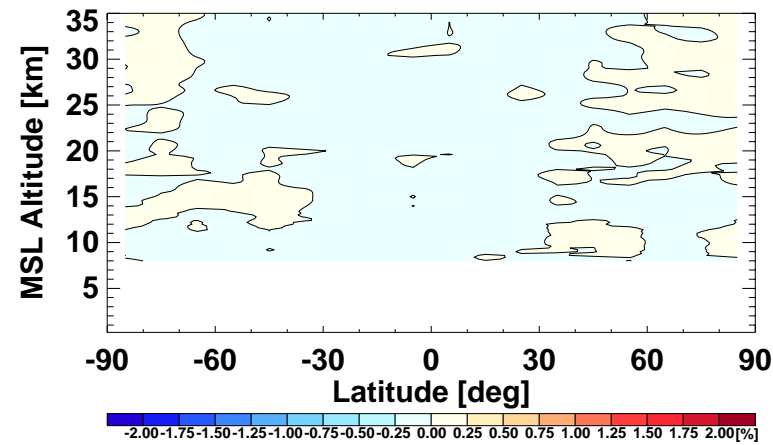

Fig. 3. Monthly mean relative refractivity deviations from the multi-satellite mean for October 2007 for the same satellites as in Fig. 2 but with the respective sampling errors subtracted. 

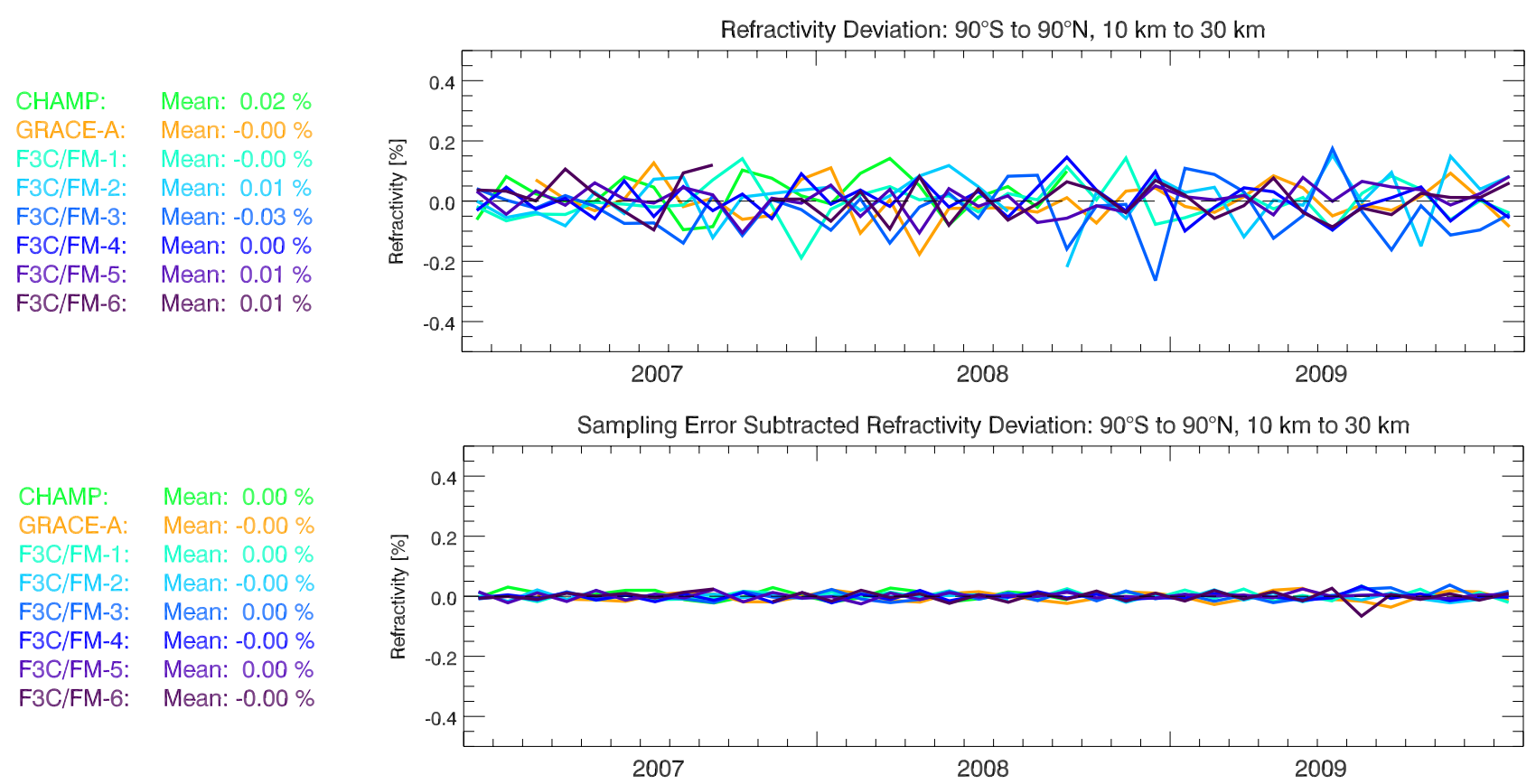

Fig. 4. Temporal evolution of global mean monthly mean single-satellite refractivity deviations from the multi-satellite mean (averaged over the entire domain from $10 \mathrm{~km}$ to $30 \mathrm{~km}$ altitude) from January 2007 to December 2009. Deviations with sampling errors included (top) and subtracted (bottom), respectively, are shown for eight satellites (listed left; showing also for each satellite the time-averaged mean value from its full period of observations).

that the estimation of the sampling error is quite accurate, i.e. ECWMF analysis fields capture the atmospheric variability reasonably well.

Figure 4 shows the temporal evolution of global mean refractivity deviations over January 2007 to December 2009. Even the differences without sampling error subtraction (top panel) only occasionally exceed $0.15 \%$ for individual months. Sampling errors largely cancel when averaging over several months and mean values for the entire available time period range from $-0.03 \%$ to $+0.02 \%$. After subtraction of the estimated sampling errors from the individual climatologies (bottom panel) the data consistency is even more convincing: values for individual months are smaller than $0.05 \%$ in almost any case, mean values for the entire time period are $0.00 \%$ for each satellite. F3C/FM6 data are not available for all months. In June and until mid-July 2009 there are only very few F3C/FM-6 data, which explains slightly larger deviations during these months.

In Fig. 5 we analyze the altitude dependence of the refractivity deviations by inspecting five altitude layers of $5 \mathrm{~km}$ width in the upper troposphere and lower stratosphere (UTLS). Up to $30 \mathrm{~km}$ altitude all records are very consistent with temporal mean values between $-0.01 \%$ and $+0.01 \%$ $(0.00 \%$ in most cases). Above $30 \mathrm{~km}$, CHAMP RO data differ from the multi-satellite mean by $-0.03 \%$. The most likely reason for this behavior is the high-altitude initialization: CHAMP bending angles at high altitudes are not biased toward the other satellite records (Fig. 1), but CHAMP data show a higher noise level. This leads to a stronger weighting of the background than in the RO data from the other satellites, and a potential bias in the background will already become visible at lower altitudes (see, e.g. Gobiet and Kirchengast, 2004; Steiner and Kirchengast, 2005; Gobiet et al., 2007, for details on initialization behavior).

\subsection{Consistency of dry temperature climatologies}

Figure 6 shows the dry temperature deviations from the multi-satellite mean. The respective sampling errors are again subtracted. Between $10 \mathrm{~km}$ and $25 \mathrm{~km}$ altitude, values for individual months hardly exceed $0.05 \mathrm{~K}$ (only $0.02 \%$ in relative terms, given temperatures are near $250 \mathrm{~K}$ or lower above about $8 \mathrm{~km}$ in the UTLS). Temporal mean values for GRACE-A and F3C do not exceed $0.02 \mathrm{~K}(0.01 \%)$ up to an altitude of $30 \mathrm{~km}$. CHAMP shows small, but systematic differences from the satellite mean by $-0.03 \mathrm{~K}(10 \mathrm{~km}$ to $15 \mathrm{~km}$ and $15 \mathrm{~km}$ to $20 \mathrm{~km}),-0.05 \mathrm{~K}(20 \mathrm{~km}$ to $25 \mathrm{~km}),-0.08 \mathrm{~K}$ $(25 \mathrm{~km}$ to $30 \mathrm{~km})$, and $-0.11 \mathrm{~K}(30 \mathrm{~km}$ to $35 \mathrm{~km})$. This increasing difference with altitude is consistent with the explanation in Sect. 3.2 above: the hydrostatic integration in the retrieval step from refractivity (density) to pressure leads to a downward propagation of high altitude initalization errors, propagating further into temperature (Gobiet and Kirchengast, 2004; Steiner and Kirchengast, 2005). A detailed 
CHAMP: Mean: $-0.03 \%$ GRACE-A: Mean: $-0.01 \%$ F3C/FM-1: Mean: $0.01 \%$ F3C/FM-2: Mean: $0.00 \%$ F3C/FM-3: Mean: $0.00 \%$ F3C/FM-4: Mean: $0.00 \%$ F3C/FM-5: Mean: $0.00 \%$ F3C/FM-6: Mean: $0.00 \%$

CHAMP: Mean: $-0.01 \%$ GRACE-A: Mean: $-0.00 \%$ F3C/FM-1: Mean: $0.00 \%$ F3C/FM-2: Mean: $0.00 \%$ F3C/FM-3: Mean: $0.00 \%$ F3C/FM-4: Mean: $-0.00 \%$ F3C/FM-5: Mean: $0.00 \%$ F3C/FM-6: Mean: $-0.00 \%$

CHAMP: GRACE-A F3C/FM-1: F3C/FM-2 F3C/FM-3: F3C/FM-4: F3C/FM-5 F3C/FM-6:

Mean: $0.00 \%$ Mean: $0.00 \%$ Mean: $0.00 \%$ Mean: $-0.00 \%$ Mean: $-0.00 \%$ Mean: $-0.00 \%$ Mean: $0.00 \%$ Mean: $-0.00 \%$

CHAMP: GRACE-A: F3C/FM-1: F3C/FM-2: F3C/FM-3 F3C/FM-4 F3C/FM-5: F3C/FM-6:

CHAMP: GRACE-A F3C/FM-1: F3C/FM-2: F3C/FM-3: F3C/FM-4: F3C/FM-5: F3C/FM-6:
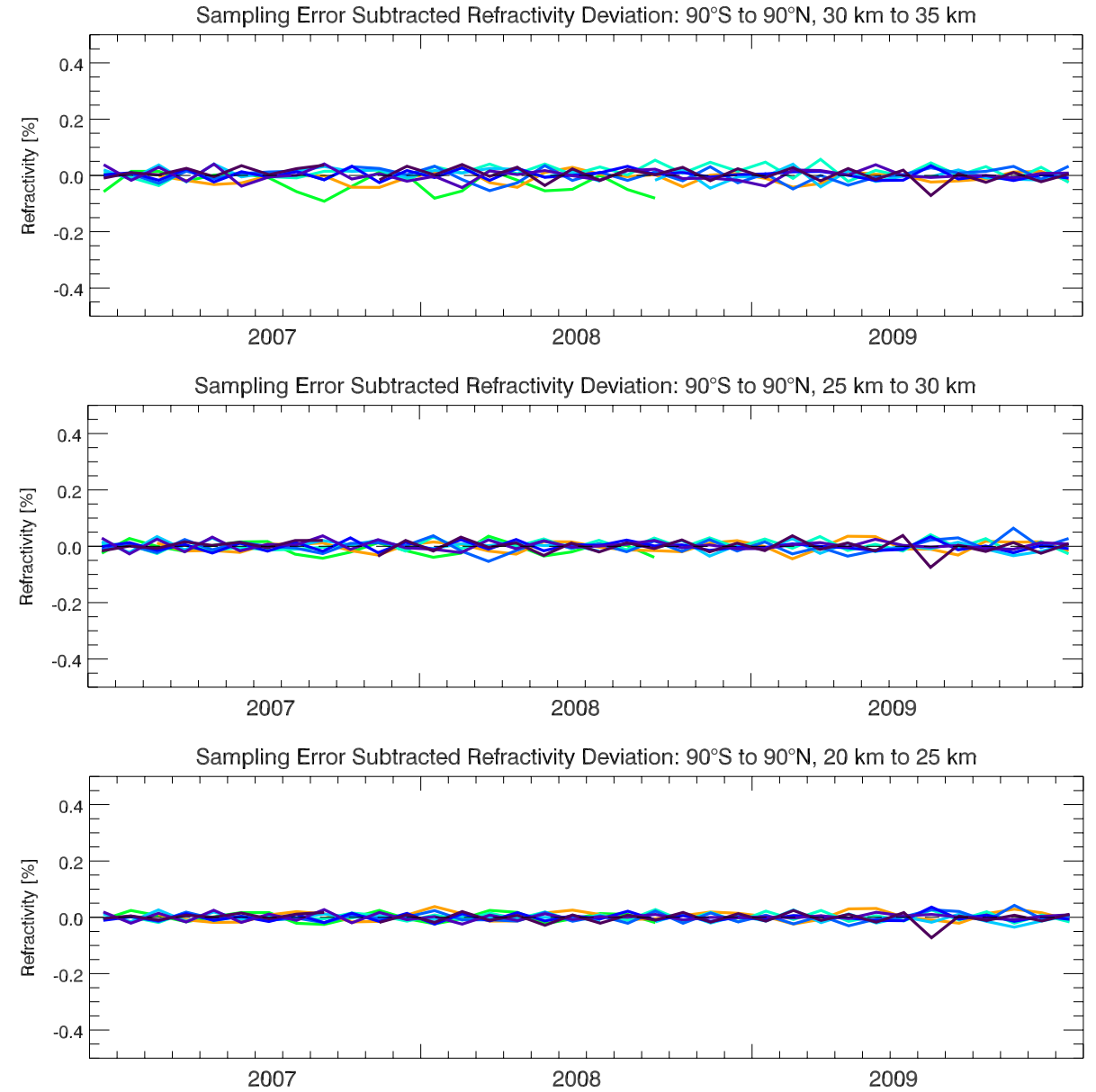

Sampling Error Subtracted Refractivity Deviation: $90^{\circ} \mathrm{S}$ to $90^{\circ} \mathrm{N}, 15 \mathrm{~km}$ to $20 \mathrm{~km}$

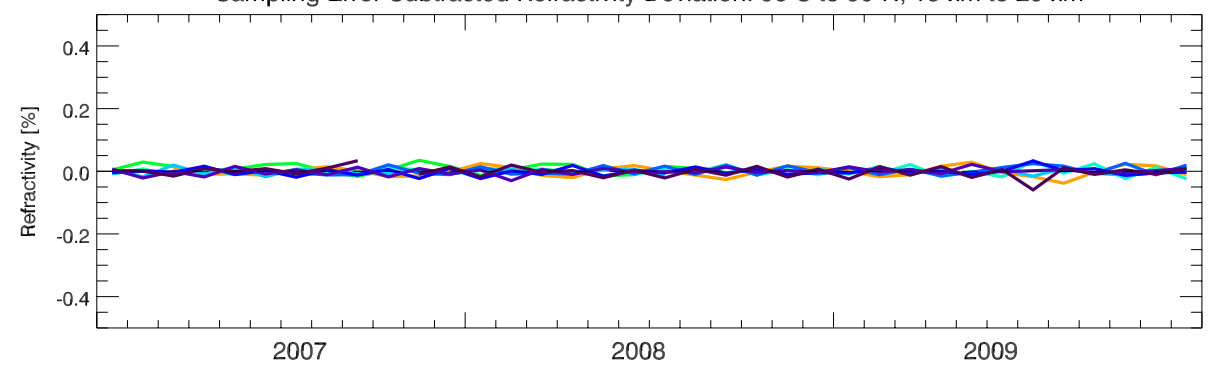

Sampling Error Subtracted Refractivity Deviation: $90^{\circ} \mathrm{S}$ to $90^{\circ} \mathrm{N}, 10 \mathrm{~km}$ to $15 \mathrm{~km}$

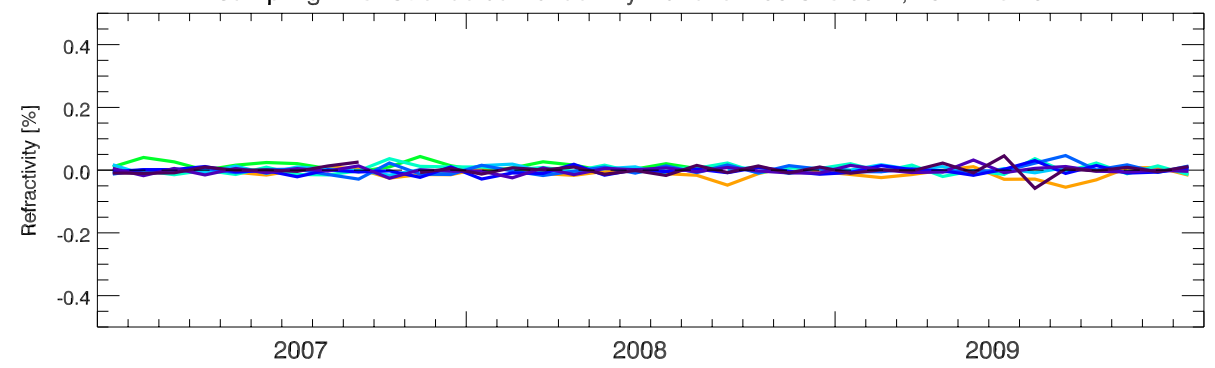

Fig. 5. Global mean monthly mean single-satellite refractivity deviations from the multi-satellite mean, after subtraction of the respective sampling errors, for five different altitude layers in the UTLS: $30 \mathrm{~km}$ to $35 \mathrm{~km}, 25 \mathrm{~km}$ to $30 \mathrm{~km}, 20 \mathrm{~km}$ to $25 \mathrm{~km}, 15 \mathrm{~km}$ to $20 \mathrm{~km}$, and $10 \mathrm{~km}$ to $15 \mathrm{~km}$ (top to bottom; same layout per panel as in Fig. 4). 


$\begin{array}{ll}\text { CHAMP: } & \text { Mean: }-0.11 \mathrm{~K} \\ \text { GRACE-A: } & \text { Mean: }-0.00 \mathrm{~K} \\ \text { F3C/FM-1: } & \text { Mean: } 0.03 \mathrm{~K} \\ \text { F3C/FM-2: } & \text { Mean: } 0.02 \mathrm{~K} \\ \text { F3C/FM-3: } & \text { Mean: } 0.01 \mathrm{~K} \\ \text { F3C/FM-4: } & \text { Mean: } 0.01 \mathrm{~K} \\ \text { F3C/FM-5: } & \text { Mean: }-0.01 \mathrm{~K} \\ \text { F3C/FM-6: } & \text { Mean: } 0.01 \mathrm{~K}\end{array}$

CHAMP: GRACE-A: F3C/FM-1: F3C/FM-2: F3C/FM-3: F3C/FM-4: F3C/FM-5: F3C/FM-6:

CHAMP: GRACE-A: F3C/FM-1: F3C/FM-2: F3C/FM-3: F3C/FM-4: F3C/FM-5: F3C/FM-6:
Mean: $-0.08 \mathrm{~K}$ Mean: $-0.01 \mathrm{~K}$ Mean: $0.02 \mathrm{~K}$ Mean: $0.01 \mathrm{~K}$ Mean: $0.00 \mathrm{~K}$ Mean: $0.01 \mathrm{~K}$ Mean: $-0.01 \mathrm{~K}$ Mean: $0.01 \mathrm{~K}$ $\begin{array}{ll}\text { CHAMP: } & \text { Mean: }-0.03 \mathrm{~K} \\ \text { GRACE-A: } & \text { Mean: } 0.00 \mathrm{~K} \\ \text { F3C/FM-1: } & \text { Mean: } 0.01 \mathrm{~K} \\ \text { F3C/FM-2: } & \text { Mean: } 0.00 \mathrm{~K} \\ \text { F3C/FM-3: } & \text { Mean: }-0.00 \mathrm{~K} \\ \text { F3C/FM-4: } & \text { Mean: } 0.00 \mathrm{~K} \\ \text { F3C/FM-5: } & \text { Mean: } 0.00 \mathrm{~K} \\ \text { F3C/FM-6: } & \text { Mean: } 0.00 \mathrm{~K}\end{array}$
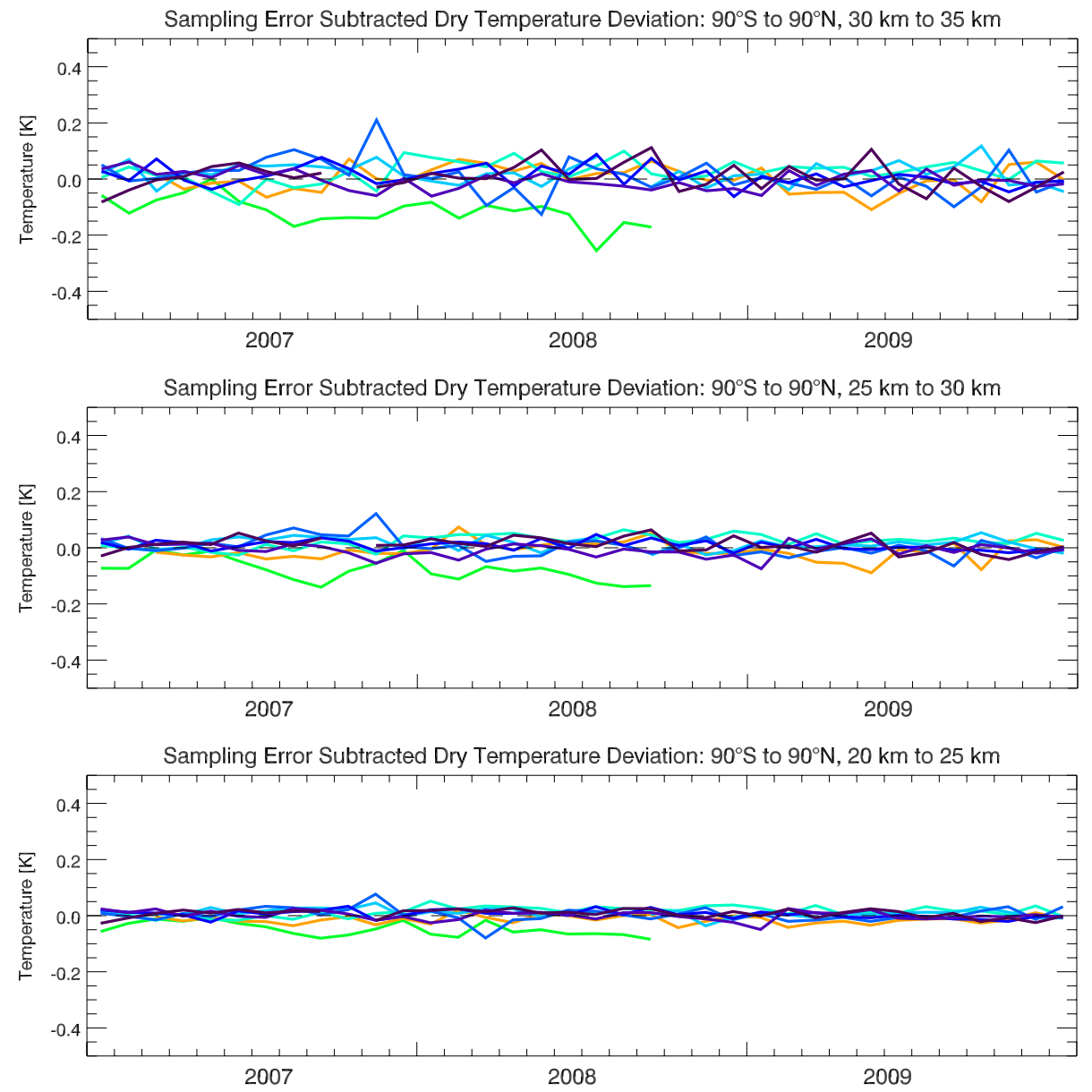

Sampling Error Subtracted Dry Temperature Deviation: $90^{\circ} \mathrm{S}$ to $90^{\circ} \mathrm{N}, 15 \mathrm{~km}$ to $20 \mathrm{~km}$

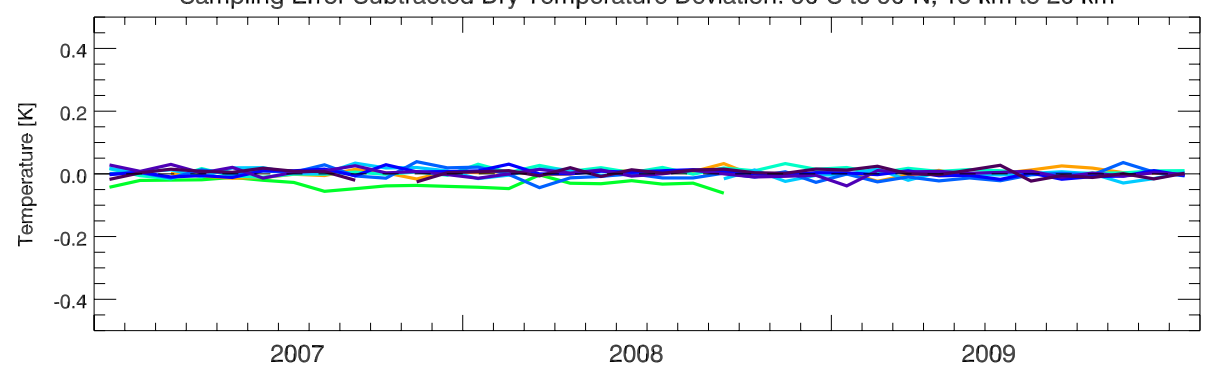

Sampling Error Subtracted Dry Temperature Deviation: $90^{\circ} \mathrm{S}$ to $90^{\circ} \mathrm{N}, 10 \mathrm{~km}$ to $15 \mathrm{~km}$

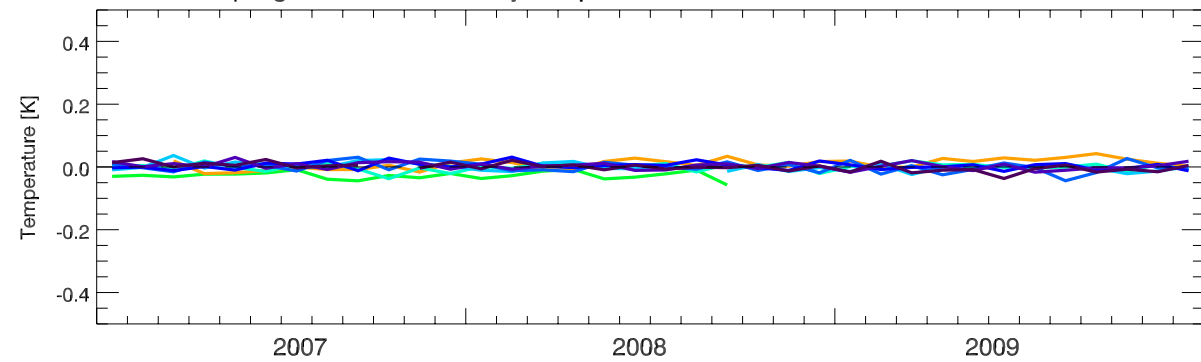

Fig. 6. Same layout as in Fig. 5 (see that caption for explanation) but here showing the dry temperature deviations for the five altitude layers considered. 
discussion of errors in atmospheric RO profiles is given by Scherllin-Pirscher et al. (2011). All satellites show somewhat higher temporal variability in the $30 \mathrm{~km}$ to $35 \mathrm{~km}$ domain.

\section{Conclusions}

We analyzed the consistency of radio occultation (RO) climatologies derived from different satellites, by applying the same profiles retrieval scheme (OPSv5.4) to excess phase and orbit data provided by UCAR/CDAAC, Boulder, CO, USA, as well as the same climatology preparation scheme (CLIPSv1.3). Refractivity climatologies from all satellites agree very well up to $30 \mathrm{~km}$ altitude, even more when the estimated respective sampling errors are subtracted. In the UTLS core region between $10 \mathrm{~km}$ and $30 \mathrm{~km}$ altitude, global mean values of relative refractivity deviations from the multisatellite mean for individual months are smaller than $0.05 \%$ in almost any case, time-averaged values for the entire time period are $0.00 \%$ for each satellite. Consistency of temperature climatologies is correspondingly high, generally within $0.05 \mathrm{~K}(0.02 \%$ relative $)$.

It should, however, be noted that this consistency is not a proof of absolute accuracy, since there is a possibility of small common systematic errors in all RO records (e.g. due to residual structural uncertainty as analyzed by Ho et al. (2009) or due to uncorrected ionospheric residuals). We found no indications for instrument degradation, temporal inhomogeneities in the RO records, or temporal trends in sampling patterns. We conclude that if applying the same processing scheme for all data, refractivity and dry temperature records from individual satellites with similar bending angle noise can be safely combined up to $30 \mathrm{~km}$ altitude (refractivity also up to $35 \mathrm{~km}$ ) to a consistent single climate record. Long-term climate records of this quality will be of substantial value for climate monitoring in the upper troposphere and lower stratosphere, underpinning the importance of long-term collection of radio occultation data for climate applications.

Acknowledgements. UCAR/CDAAC (Boulder, CO, USA) is acknowledged for the provision of CHAMP, GRACE-A, and F3C excess phase and orbit data, ECMWF (Reading, UK) for access to their global forecast and analysis data. J. Fritzer (Wegener Center) is thanked for his efforts in OPS system development and operations. This work was funded by the Austrian Science Fund (FWF; BENCHCLIM project P22293-N21, TRENDEVAL project P21642-N21) and regarding OPS development by ESA/ESTEC Noordwijk (ProdexCN2 project) and FFG/ALR Austria (ASAP/EOPSCLIM project). The National Center for Atmospheric Research is supported by the National Science Foundation.

Edited by: K. B. Lauritsen

\section{References}

Anthes, R. A., Bernhardt, P. A., Chen, Y., Cucurull, L., Dymond, K. F., Ector, D., Healy, S. B., Ho, S. P., Hunt, D. C., Kuo, Y.-H., Liu, H., Manning, K., McCormick, C., Meehan, T. K., Randel, W. J., Rocken, C., Schreiner, W. S., Sokolovskiy, S. V., Syndergaard, S., Thompson, D. C., Trenberth, K. E.,Wee, T. K., Yen, N. L., and Zeng, Z.: The COSMIC/FORMOSAT-3 mission-early results, B. Am. Meteorol. Soc., 89, 313-333, 2008.

Beyerle, G., Schmidt, T., Michalak, G., Heise, S., Wickert, J., and Reigber, C.: GPS radio occultation with GRACE: Atmospheric Profiling utilizing the zero difference technique, Geophys. Res. Lett., 32, L13806, doi:10.1029/2005GL023109, 2005.

Borsche, M., Gobiet, A., Steiner, A.K., Foelsche, U., Kirchengast, G., Schmidt, T., and Wickert, J.: Pre-Operational Retrieval of Radio Occultation based Climatologies, in: Atmosphere and Climate: Studies by Occultation Methods, edited by: Foelsche, U., Kirchengast, G., and Steiner, A. K., Springer, Berlin-Heidelberg, 315-323, doi:10.1007/3-540-34121-8_26, 2006.

Borsche, M., Kirchengast, G., and Foelsche, U.: Tropical tropopause climatology as observed with radio occultation measurements from CHAMP compared to ECMWF and NCEP analyses, Geophys. Res. Lett., 34, L03702, doi:10.1029/2006GL027918, 2007.

Cardinali, C.: Monitoring the observation impact on the short-range forecast, Q. J. Roy. Meteorol. Soc., 135, 239-250, 2009.

Foelsche, U., Kirchengast, G., and Steiner, A. K.: Global climate monitoring based on CHAMP/GPS radio occultation data, in: First CHAMP Mission Results for Gravity, Magnetic and Atmospheric Studies, edited by: Reigber, C., Lühr, H., and Schwintzer, P., Springer, Berlin Heidelberg, 397-407, 2003.

Foelsche, U., Gobiet, A., Löscher, A., Kirchengast, G., Steiner, A. K., Wickert, J., and Schmidt, T.: The CHAMPCLIM project: An overview, in: Earth observation with CHAMP - results from three years in orbit, edited by: Reigber, C., Lühr, H., Schwintzer, P., and Wickert, J., Springer, Berlin Heidelberg, 615-620, 2005.

Foelsche, U., Borsche, M., Steiner, A.K., Gobiet, A., Pirscher, B., Kirchengast, G., Wickert, J., and Schmidt, T.: Observing Upper Troposphere-Lower Stratosphere Climate with Radio Occultation Data from the CHAMP Satellite, Clim. Dynam., 31, 49-65, doi:10.1007/s00382-007-0337-7, 2008a.

Foelsche, U., Kirchengast, G., Steiner, A. K., Kornblueh, L., Manzini, E., and Bengtsson, L.: An observing system simulation experiment for climate monitoring with GNSS radio occultation data: Setup and test bed study, J. Geophys. Res., 113, D11108, doi:10.1029/2007JD009231, 2008b.

Foelsche, U., Pirscher, B., Borsche, M., Kirchengast, G., and Wickert, J.: Assessing the climate monitoring utility of radio occultation data: from CHAMP to FORMOSAT3/COSMIC, Terr. Atmos. Oceanic Sci., 20, 155-170, doi:10.3319/TAO.2008.01.14.01(F3C), 2009.

Gobiet, A. and Kirchengast, G.: Advancements of GNSS radio occultation retrieval in the upper stratosphere for optimal climate monitoring utility, J. Geophys. Res., 109, D24110, doi:10.1029/2004JD005117, 2004.

Gobiet, A., Foelsche, U., Steiner, A. K., Borsche, M., Kirchengast, G., and Wickert, J.: Climatological validation of stratospheric temperatures in ECMWF operational analyses with CHAMP radio occultation data, Geophys. Res. Lett., 32, L12806, doi:10.1029/2005GL022617, 2005. 
Gobiet, A., Kirchengast, G., Manney, G. L., Borsche, M., Retscher, C., and Stiller, G.: Retrieval of temperature profiles from CHAMP for climate monitoring: intercomparison with Envisat MIPAS and GOMOS and different atmospheric analyses, Atmos. Chem. Phys., 7, 3519-3536, doi:10.5194/acp-7-3519-2007, 2007.

Hajj, G. A., Kursinski, E. R., Romans, L. J., Bertiger, W. I., and Leroy, S. S.: A Technical Description of Atmospheric Sounding by GPS occultation, J. Atmos. Solar-Terr. Phys., 64, 451-469, 2002.

Hajj, G. A, Ao, C. O., Iijima, B. A., Kuang, D., Kursinski, E. R., Mannucci, A. J., Meehan, T. K., Romans, L. J., de la Torre Juarez, M., and Yunck, T. P.: CHAMP and SACC atmospheric occultation results and intercomparisons, J. Geophys. Res., 109, D06109, doi:10.1029/2003JD003909, 2004.

Hardy, K. R., Hajj, G. A., and Kursinski, E. R.: 1994: Accuracies of atmospheric profiles obtained from GPS occultations, Int. J. Sat. Comm., 12, 463-473, 1994.

Healy, S. B.: Smoothing radio occultation bending angles above 40 km, Ann. Geophys., 19, 459-468, 2001, http://www.ann-geophys.net/19/459/2001/.

Healy, S. B.: Forecast impact experiment with a constellation of GPS radio occultation receivers, Atmos. Sci. Lett., 9, 111-118, 2008.

Hedin, A. E.: Extension of the MSIS thermosphere model into the middle and lower atmosphere, J. Geophys. Res., 96, 1159-1172, 1991.

Ho, S.-P., Goldberg, M., Kuo, Y.-H., Zou, C.-Z., and Schreiner, W.: Calibration of temperature in the lower stratosphere from microwave measurements using COSMIC radio occultation data: Preliminary results, Terr. Atmos. Ocean. Sci., 20, 87-100, 2009a.

Ho, S.-P., Kirchengast, G., Leroy, S., Wickert, J., Mannucci, A. J., Steiner, A., Hunt, D., Schreiner, W., Sokolovskiy, S., Ao, C., Borsche, M., von Engeln, A., Foelsche, U., Heise, S., Iijima, B., Kuo, Y.-H., Kursinski, E. R., Pirscher, B., Ringer, M., Rocken, C., and Schmidt, T.: Estimating the uncertainty of using GPS radio occultation data for climate monitoring: Intercomparison of CHAMP refractivity climate records 2002-2006 from different data centers, J. Geophys. Res., 114, D23107, doi:10.1029/2009JD011969, 2009b.

Kursinski, E. R., Hajj, G. A., Schofield, J. T., Linfield, R. P., and Hardy, K. R.: Observing Earth's atmosphere with radio occultation measurements using the Global Positioning System, J. Geophys. Res., 102, 23429-23465, 1997.

Leroy, S. S., Dykema, J. A., and Anderson, J. G.: Climate benchmarking using GNSS occultation, in: Atmosphere and Climate: Studies by Occultation Methods, edited by: Foelsche, U., Kirchengast, G., and Steiner, A. K., Springer, Berlin-Heidelberg, 287-301, doi:10.1007/3-540-34121-8_24, 2006a.

Leroy, S. S., Anderson, J. G., and Dykema, J. A.: Testing climate models using GPS radio occultation: A sensitivity analysis, J. Geophys. Res., 111, D17105, doi:10.1029/2005JD006145, $2006 b$.

Luntama, J.-P., Kirchengast, G., Borsche, M., Foelsche, U., Steiner, A. K., Healy, S., von Engeln, A., O'Clerigh, E., and Marquardt, C.: Prospects of the EPS GRAS Mission for Operational Atmospheric Applications, B. Am. Meteorol. Soc., 89, 1863-1875, doi:10.1175/2008BAMS2399.1, 2008.

Pirscher, B.: Multi-Satellite Climatologies of Fundamental Atmo- spheric Variables From Radio Occultation and Their Validation, Ph.D. thesis, Wegener Center for Climate and Global Change, University of Graz, Austria, 2010.

Pirscher, B., Foelsche, U., Lackner, B. C., and Kirchengast, G.: Local time influence in single-satellite radio occultation climatologies from Sun-synchronous and non-Sun-synchronous satellites, J. Geophys. Res., 112, D11119, doi:10.1029/2006JD007934, 2007.

Rieder, M. J., and Kirchengast, G.: Error analysis and characterization of atmospheric profiles retrieved from GNSS occultation data, J. Geophys. Res., 106, 31755-31770, 2001.

Ringer, M. A. and Healy, S. B.: Monitoring twenty-first century climate using GPS radiooccultation bending angles, Geophys. Res. Lett., 35, L05708, doi:10.1029/2007GL032462, 2008.

Scherllin-Pirscher, B., Steiner, A. K., Kirchengast, G., Kuo, Y.-H., and Foelsche, U.: Empirical analysis and modeling of errors of atmospheric profiles from GPS radio occultation, Atmos. Meas. Tech., 4, 1875-1890, doi:10.5194/amt-4-1875-2011, 2011.

Schmidt, T., Heise, S., Wickert, J., Beyerle, G., and Reigber, C.: GPS radio occultation with CHAMP and SAC-C: global monitoring of thermal tropopause parameters, Atmos. Chem. Phys., 5, 1473-1488, doi:10.5194/acp-5-1473-2005, 2005.

Schmidt, T., Wickert, J., and Haser, A.: Variability of the upper troposphere and lower stratosphere observed with GPS radio occultation bending angles and temperatures, Adv. Space Res., 46, 150-161, doi:10.1016/j.asr.2010.01.021, 2010.

Schreiner, W., Rocken, C., Sokolovskiy, S., Syndergaard, S., and Hunt, D.: Estimates of the precision of GPS radio occultations from the COSMIC/FORMOSAT-3 mission, Geophys. Res. Lett., 34, L04808, doi:10.1029/2006GL027557, 2007.

Schreiner, W. S., Rocken, C., Sokolovskiy, S., and Hunt, D. C.: Quality assessment of COSMIC/FORMOSAT-3 GPS radio occultation data derived from single- and double-difference atmospheric excess phase processing, GPS Solutions, 14, 13-22, doi:10.1007/s10291-009-0132-5, 2009.

Schroeder, T., Leroy, S. S., Stendel, M., and Kaas, E.: Validating the microwave sounding unit stratospheric record using GPS occultation, Geophys. Res. Lett., 30, 1734, doi:10.1029/2003GL017588, 2003.

Sokolovskiy, S., Kuo, Y.-H., Rocken, C., Schreiner, W. S., Hunt, D., and Anthes, R. A.: Monitoring the atmospheric boundary layer by GPS radio occultation signals recorded in the open-loop mode, Geophys. Res. Lett., 33, L12813, doi:10.1029/2006GL026112, 2006.

Sokolovskiy, S., Schreiner, W., Rocken, C., and Hunt, D.: Optimal noise filtering for the Ionospheric correction of GPS radio occultation signals, J. Atmos. Oceanic Technol., 26, 1398-1403, 2009.

Steiner, A. K. and Kirchengast, G.: Error analysis for GNSS radio occultation data based on ensembles of profiles from end-to-end simulations, J. Geophys. Res., 110, D15307, doi:10.1029/2004JD005251, 2005.

Steiner, A. K., Kirchengast, G., Foelsche, U., Kornblueh, L., Manzini, E., and Bengtsson, L.: GNSS occultation sounding for climate monitoring, Phys. Chem. Earth (A), 26, 113-124, 2001.

Steiner, A. K., Kirchengast, G., Borsche, M., Foelsche, U., and Schoengassner, T.: A multi-year comparison of lower stratospheric temperatures from CHAMP radio occultation data with MSU/AMSU records, J. Geophys. Res., 112, D22110, 
doi:10.1029/2006JD008283, 2007.

Steiner, A. K., Kirchengast, G., Lackner, B. C., Pirscher, B., Borsche, M., and Foelsche, U.: Atmospheric temperature change detection with GPS radio occultation 1995 to 2008, Geophys. Res. Lett., 36, L18702, doi:10.1029/2009GL039777, 2009.

von Engeln, A.: A first test of climate monitoring with radio occultation instruments: Comparing two processing centers, Geophys. Res. Lett., 33, L22705, doi:10.1029/2006GL027767, 2006.

von Engeln, A., Teixeira, J., Wickert, J., and Buehler, S. A.: Using CHAMP radio occultation data to determine the top altitude of the planetary boundary layer, Geophys. Res. Lett., 32, L06815, doi:10.1029/2004GL022168, 2005.

von Engeln, A., Healy, S., Marquardt, C., Andres, Y., and Sancho, F.: Validation of operational GRAS radio occultation data, Geophys. Res. Lett., 36, L17809, doi:10.1029/2009GL039968, 2009.

Vorob'ev, V. V. and Krasil'nikova, T. G.: Estimation of the accuracy of the atmospheric refractive index recovery from Doppler shift measurements at frequencies used in the NAVSTAR system, Phys. Atmos. Ocean, 29, 602-609, 1994.
Wickert, J., Reigber, C., Beyerle, G., König, R., Marquardt, C., Schmidt, T., Grunwaldt, L., Galas, R., Meehan, T. K., Melbourne, W. G., and Hocke, K.: Atmosphere sounding by GPS radio occultation: first results from CHAMP, Geophys. Res. Lett., 28, 3263-3266, 2001.

Wickert, J., Schmidt, T., Beyerle, G., König, R., Reigber, C., and Jakowski, N.: The radio occultation experiment aboard CHAMP: operational data processing and validation of atmospheric parameters, J. Meteorol. Soc. Jpn., 82, 381-395, 2004.

Yuan, L. L., Anthes, R. A., Ware, R. H., Rocken, C., Bonner, W. D., Bevis, M. G., and Businger, S.: Sensing Climate Change Using the Global Positioning System, J. Geophys. Res., 98, 1492514937, 1993. 